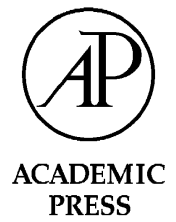

Available online at www.sciencedirect.com

\title{
Economic benefits of management reform in the northern Gulf of Mexico reef fish fishery
}

\author{
Quinn Weninger ${ }^{\mathrm{a}, *}$ and James R. Waters ${ }^{\mathrm{b}}$ \\ a Department of Economics, Iowa State University, 260 Heady Hall, Ames, IA 50011-1070, USA \\ ${ }^{\mathrm{b}}$ US Department of Commerce, National Marine Fisheries Service, USA
}

\begin{abstract}
Controlled access management in the northern Gulf of Mexico commercial reef fish fishery has not achieved key management objectives. We estimate the economic benefits of replacing controlled access with tradable harvest permits. Results suggest that eliminating market gluts caused by periodic seasonal closures could have raised revenues by $\$ 3.206 \mathrm{~m}$ in 1993 , the year of our data. Eliminating per-trip catch limits and seasonal closures could have reduced harvest costs by $\$ 8.078 \mathrm{~m}$. The total 1993 potential benefits, at $\$ 11.284 \mathrm{~m}$, suggest property rights-based management is an attractive alternative for the northern Gulf reef fish fishery.

(C) 2003 Elsevier Science (USA). All rights reserved.
\end{abstract}

Keywords: Rights-based management; Harvest efficiency; Rent generation

\section{Introduction}

Controlled access management in the northern Gulf of Mexico commercial reef fish fishery, including vessel entry restrictions, a total allowable catch (TAC) policy that is enforced with periodic fishery closures, and per-trip catch limits for qualifying vessels, has failed to achieve key management objectives. The National Marine Fisheries Service has classified the highest valued species in the northern Gulf of Mexico reef fish complex, red snapper, and several other species as overfished. Controlled access regulations curb fishing mortality but raise fleet harvesting costs. Periodic closures create a race for fish, with marketing gluts and depressed dockside prices. The race for fish also lures vessels to sea in hazardous weather and has been cited as the cause of recent

\footnotetext{
${ }^{*}$ Corresponding author.

E-mail address: weninger@iastate.edu (Q. Weninger).
} 
vessel sinkings. ${ }^{1}$ Managers and industry agree that management reform is needed but a consensus has not been reached as to which management alternative is best.

This paper provides an ex ante estimate of potential economic benefits under tradable harvest permits, one of the management alternatives being considered by industry and the Gulf of Mexico Fishery Management Council. ${ }^{2}$ Under tradable permits, or property rights-based (RB) management, fishing mortality is controlled by allocating exclusive, tradable rights to harvest specified quantities of fish during each harvest season. RB programs promise to generate resource rents but managers and industry contemplating a RB approach must do so without knowing the extent of the economic benefits. An ex ante estimate of potential rent gains thus provides vital information that will undoubtedly assist in the management reform process.

We predict long-run equilibrium harvesting and marketing practices expected to prevail in the reef fish fishery with tradable harvest permits for reef fish. Experience with other RB-managed fisheries, discussions with industry and managers, a survey of reef fish fishers, and careful attention to the economic incentives that are implicit in tradable permit programs are used in this first step. Conditional on predicted practices, we estimate the net revenues from harvesting and marketing the aggregate reef fish catch in 1993, the year of our data. ${ }^{3}$

The analysis identifies two main sources of economic gain. First, on the revenue side, elimination of the seasonal closures, currently used to conserve red snapper stocks, will allow fishers to spread the catch more evenly throughout each year. ${ }^{4}$ The red snapper fishery was open for 95 of a possible 365 days in 1993, causing large quantities of red snapper to reach consumer markets in a short time period. Eliminating seasonal closures is predicted to increase average dockside prices. The analysis finds that in 1993 revenue gains between $\$ 2.438 \mathrm{~m}$ and $\$ 3.977 \mathrm{~m}$ were possible without a seasonal closure (all values are reported in 1993 dollars).

The remaining benefits are harvest cost savings predicted to emerge as input controls are replaced with tradable harvest permits. The analysis predicts that $\mathrm{RB}$ vessels will adjust permit holdings to exploit economies of scale and scope, resulting in increased catch per vessel, a significant reduction in fleet size, and lower fleet harvest costs. Results suggest that between 29 and 70 vessels, harvesting reef fish year round, could harvest the same quantity of reef fish that was harvested by 387 vessels active in 1993. Considerable fleet downsizing predicted under RB management will result in further cost savings as harvesting responsibilities are redistributed to the most efficient vessels from among the active reef fish fleet. Total 1993 harvest cost savings are estimated to range between $\$ 7.860 \mathrm{~m}$ and $\$ 8.416 \mathrm{~m}$.

Combined revenue gains and cost savings in the commercial sector, estimated at $\$ 11.283 \mathrm{~m}$ in 1993 were likely available throughout the controlled access management regime, 1990-2001,

\footnotetext{
${ }^{1}$ On April 2, 2001, the vessel Wayne's Pain sank in bad weather, 85 miles off Marsh Island, LA. The vessel's captain stated, "I wouldn't have been out there then except the derby was on" (Washington Bureau report, 2001). The derby refers to a 10 day season opening for red snapper which began on April 1.

${ }^{2}$ Dupont [8], Squires and Kirkley [21,22], and Squires et al. [20] provide ex ante estimates of the potential gains from tradable permits. Studies examining the performance of existing programs are increasingly available, e.g. [16].

${ }^{3}$ It is possible that new marketing and harvesting practices will emerge when the fishery is switched to RB management. Such new practices will be adopted only if they are more profitable than currently available ones. Our estimates thus provide a lower bound on the rent gains available under RB management.

${ }^{4}$ Wilen and Homans [30] recognized early the importance of market side benefits from RB management. See also [4].
} 
suggesting RB management should be given serious consideration for reef fish in the northern Gulf.

The next section discusses industry background and summarizes the regulatory history in the northern Gulf reef fish fishery. Section 3 presents a directional distance function (DDF) model of a multiproduct harvest technology, which is used to study harvesting efficiency under controlled access management and predict cost savings under RB management. Section 4 presents results including estimates of revenue gains. Sensitivity analysis and other institutional considerations are discussed in Section 5, and concluding remarks appear in Section 6.

\section{Industry background and regulations}

The reef fish fishery in the Gulf of Mexico is a complex of bottom-dwelling species consisting of red, vermilion, and other snapper species, yellowedge, gag, warsaw and other species of groupers, amberjacks, triggerfish, porgies, tilefish, and a host of others. The region of the fishery studied in this paper extends west from Panama City, Florida to the Texas-Mexico border. Management problems in the eastern Gulf reef fish fishery are similar in character to those in the west, however species composition and gear types differ. Space limitations do not permit a comprehensive analysis of both regions.

An average of 467 vessels participated in the northern reef fish fishery during 1993-2001. A typical reef fishing trip involves steaming to a selected site which may be located in excess of 100 miles from port. A weighted vertical line containing several baited hooks is lowered to the desired depth. Once reef fish are lured to the bait the line is recovered either with a hydraulic or handpowered winch. Vessels often search multiple sites on a single trip before returning to port. In the absence of per-trip catch limits, most trips average less than 7 days with median trip length equal to 3-4 days. The main (primary) harvesting inputs are the capital services provided by the vessel, fuel used during steaming and fishing, captain and crew labor services, bait and ice, and food and supplies for captain and crew.

A Gulf of Mexico Reef Fish Fishery Management Plan, hereafter FMP, was implemented in November 1984. The FMP enacted a few simple harvesting regulations that prohibited fishing practices considered destructive to the marine environment. Since enactment of the original FMP, a series of amendments and reporting requirements were introduced to assist ongoing management. The management actions contained in these amendments vary but most are additional measures to reduce fishing mortality by an increasingly skilled commercial fleet and an expanding for-hire and recreational sector.

The highest-valued and most regulated reef fish species in the northern Gulf is red snapper. Amendment 1 set a total allowable catch (TAC) for red snapper, allocating 51\% to the commercial sector and $49 \%$ to the recreational sector. The commercial TAC was set at $3.10 \mathrm{~m}$ pounds in 1990, was reduced to $2.04 \mathrm{~m}$ pounds from 1991 to 1992 , increased to $3.06 \mathrm{~m}$ pounds during 1993-1995 and increased again to 4.65m pounds during 1996-2000. Amendment 4 (May, 1992) imposed a temporary moratorium on new commercial reef fish entry permits. An emergency rule, effective December 30, 1992, created a red snapper endorsement system that restricted pertrip catch quantities. Reef fish permit holders who could demonstrate a harvest quantity of at least 5000 pounds of red snapper in two of three years during 1990-1992 were granted an endorsement 
to catch a maximum of 2000 pounds of red snapper per trip. All other qualified vessels were restricted to harvest a maximum of 200 pounds of red snapper per trip. The endorsement system was in place from 1993-1997. In 1998, a licensing system was adopted, which granted 138 class 1 licenses to endorsement permit holders and 8 other qualifying fishers. Class 2 permits were granted to 559 vessel owner/operators. Class 1 licenses allow 2000 pounds of red snapper per trip, while class 2 licenses allow a maximum of 200 pounds of red snapper per trip.

Fishery closures are used with the endorsement system to enforce the red snapper TAC. Prior to 1990, the red snapper season lasted 365 days. From 1991 to 2000, the red snapper fishing was limited to $236,95,95,78,51,77,74,72,70$ and 76 days, respectively.

Closures initiated a derby fishery which is considered responsible for many of the current management problems [24,27]. The Council proposed an individual transferable quota management program for the commercial red snapper fishery, to begin in 1996. However, a Congressional action in late 1995 prohibited its implementation. Congress imposed a moratorium on RB management in US fisheries pending a thorough review of their effects. This moratorium is extended through 2002.

The nature of the controlled access regulations suggest red snapper revenue gains and fleet harvesting cost savings will be important sources of benefit under RB management. Eliminating seasonal closures and marketing gluts is expected to raise dockside prices (see also $[4,14,15]$ ). Replacing input controls with secure harvest rights will encourage harvesting efficiency and reduce average harvesting costs. For example, medium size vessels (30-40 ft in length) are capable of transporting up to 5000 pounds of properly iced fish, while large vessels can properly ice up to 50,000 pounds of fish. ${ }^{5}$ Per-trip catch limits thus restrict red snapper harvest levels for many vessels operating in the fishery. Under red snapper seasonal closures vessel services either remain idle or are allocated to harvest other species during closures. Industry sources and log book data indicate vessels are capable of fishing 120-135 days per year. Seasonal lengths in the range of 50100 days thus restrict the allocation of fishing effort to red snapper production. Lastly, secure harvest rights provide a mechanism to reduce fleet size and redistribute harvest responsibilities to cost efficient vessels.

The next section presents a model of a multiproduct harvest technology which is used to examine economic distortions under controlled access management, and to characterize vessel harvesting practices expected under RB management.

\section{Model of the harvest technology}

Consider a representative vessel that allocates inputs $x \in \mathfrak{R}_{+}^{N}$ to produce outputs $y \in \mathfrak{R}_{+}^{M}$ during a given calendar period. In a regulated fishery, feasible input-output combinations depend on stock abundance and the regulations used to prevent overfishing. Denote the feasible set as

$$
T(S, R)=\{(x, y) \mid x \text { can produce } y \text { given } S \text { and } R\},
$$

where $S$ is an index of stock abundance and $R$ denotes regulations; $T(S, R)$ is assumed to be closed and convex. Input-output disposibility assumptions are discussed below.

\footnotetext{
${ }^{5}$ Felix Cox, personal communication, 2001.
} 
The directional distance function (DDF) provides a complete functional representation of the feasible set

$$
\vec{D}\left(x, y ; g_{x}, g_{y}\right)=\max \left\{\beta \in \mathfrak{R} \mid\left(x-\beta g_{x}, y+\beta g_{y}\right) \in T(S, R)\right\},
$$

where $g_{x} \in \mathfrak{R}_{+}^{N}, g_{y} \in \mathfrak{R}_{+}^{M}, g \equiv\left(g_{x}, g_{y}\right) \neq\left(0_{N}, 0_{M}\right)$, is a directional vector. The DDF gives the maximal translation of activity $(x, y)$ in the reference direction $\left(-g_{x}, g_{y}\right)$ that keeps the translated activity in the feasible set. It should be emphasized that the DDF in Eq. (2) is conditional on stock abundance and regulation since it is defined relative to $T(S, R)$. This dependence is suppressed only for notational convenience. See Chambers, Chung and Färe [5] and Färe and Grosskopf [10] for a complete discussion of the DDF and its properties.

The DDF conveniently measures technical efficiency. When $\vec{D}\left(x, y \mid g_{x}, g_{y}\right)=0$, no feasible translation is possible, indicating technical efficiency. When $\vec{D}\left(x, y \mid g_{x}, g_{y}\right)>0$ activity $(x, y)$ is located in the interior of $T(S, R)$. The technically efficient activity level is obtained directly as $\left(x-\vec{D}\left(x, y \mid g_{x}, g_{y}\right) g_{x}, y+\vec{D}\left(x, y \mid g_{x}, g_{y}\right) g_{y}\right)$.

The DDF generalizes more commonly used distance functions. At directional vectors $g_{x}=x$ and $g_{y}=0_{M}, \vec{D}\left(x, y \mid x, 0_{M}\right)=1-D_{i}(x, y)^{-1}$, where $D_{i}(x, y)$ is the Shephard input distance function. ${ }^{6}$ The reciprocal of the Shephard input distance function, the Farrell-Debreu measure of technical efficiency, computes the largest feasible contraction of the observed input bundle to the boundary of the production set. The Farrell-Debreu measure is contained in the unit interval, and $D_{i}(x, y)^{-1}=1$ indicates technical efficiency as no radial contraction of the input vector is possible.

The minimum cost function may be expressed as

$$
C(y, w)=\min _{x}\left\{w\left(x-\vec{D}\left(x, y \mid x, 0_{M}\right) \cdot x\right)\right\} .
$$

The ratio of the frontier to the actual cost incurred by a fishing vessel, $O(y, x, w)=C(y, w) / w x$ provides a useful measure of cost efficiency. If $O(y, x, w)$ takes the value 1 , activity $(x, y)$ is located on the cost frontier. Following Färe et al. [12], $O(y, x, w)$ can be decomposed as

$$
O(y, x, w)=D_{i}(x, y)^{-1} \cdot A E(x, y, w),
$$

where $A E(y, x, w)$ is the component of cost inefficiency that results from employing the wrong input mix given input prices $w$. When $A E(x, y, w)=1, x$ is input-allocatively efficient given output $y$ and input prices $w$. When $D_{i}(x, y)^{-1}=A E(x, y, w)=1$ activity $(x, y)$ is located on the cost frontier as it is both technically and input-allocatively efficient.

Setting the directional vector to $g_{x}=x$ and $g_{y}=0_{m}$, yields the following measure of scale efficiency (see [12]);

$$
\overrightarrow{S E}(x, y)=\frac{1-\vec{D}^{C R S}\left(x, y \mid x, 0_{m}\right)}{1-\vec{D}^{V R S}\left(x, y \mid x, 0_{m}\right)},
$$

where the numerator (denominator) is 1 minus the DDF under a reference technology exhibiting constant (variable) returns to scale. A value of $\overrightarrow{S E}(x, y)<1$ indicates that the activity $(x, y)$ is scale inefficient, either due to operation in a region of increasing or decreasing returns to scale. The

\footnotetext{
${ }^{6}$ The Shephard input distance function is defined as $D_{i}(x, y)=\sup \{\lambda:(x / \lambda, y) \in T\}$.
} 
specific cause of the scale inefficiency can be determined with further comparison to the DDF under a reference technology exhibiting non-decreasing returns to scale. Finally, the FarrellDebreu measure of technical efficiency and $\overrightarrow{S E}(x, y)$ are used to decompose inefficiency into a component due to purely technical inefficiency, and component due to production in a region of non-constant returns to scale. An analysis of scale inefficiency and its decomposition is demonstrated in the next section.

\section{Data and estimation}

Data are from an extensive cost survey of 99 vessels operating in the northern Gulf region in 1993 (see [26] for a detailed description of the survey design). Cost survey data are linked to the National Marine Fisheries Service Log Book reporting system which maintains detailed records of harvest, trip length, and crew information.

The 99 sample vessels harvested 90 different species in 1993 for a total of $2.69 \mathrm{~m}$ pounds of fish. Reef fish species comprised $83.3 \%$ of the total pounds harvested and non-reef fish species such as king mackerel, yellowfin tuna, bonito, and wahoo comprised $16.7 \%$ of the total. ${ }^{7}$ A much smaller group of species made up the bulk of the catch. The 10 largest volume species account for $88.7 \%$ of the sample vessel catch. Red snapper represents the largest component accounting for $47.4 \%$ of harvest.

Empirical tractability requires that harvested species be aggregated into output groups. Industry participants and managers were consulted to identify species that are harvested using similar methods, and similar inputs. It was determined that species within the reef fish complex can be found at different depths and may be more active at different times of day, but are harvested at similar locations using the same hook and line technology. In contrast, non-reef fish species are harvested at different locations and with different methods than reef fish. Based on this information we aggregate species into three output groups. The first output category, $y_{1}$, red snapper is subject to regulations not imposed for other reef fish species. The second output category, $y_{2}$, aggregates 80 other reef fish species. Within this group, vermilion snapper (28.9\%), yellowedge grouper (19.8\%), and greater amberjack $(6.4 \%)$, make up the largest component. The third output category, $y_{3}$, includes all non-reef fish, and is comprised primarily of king mackerel $(69.7 \%)$, and yellowfin tuna $(24.1 \%)$. Harvested quantities within each output category are aggregated linearly. The aggregation procedure assumes that optimal input choices and aggregate output levels can be chosen independently of the mix of species within each output category. The harvest technology is thus assumed to exhibit weak output separability. Linear aggregation implies a constant rate of transformation among species within each output group.

Table 1 reports average output and standard deviation of output for the 99 sample vessels at the trip and seasonal level. Despite red snapper harvest restrictions, vessels on average harvested more red snapper per trip and per season than all other reef fish species. Table 1 does reveal evidence of

\footnotetext{
${ }^{7}$ Fishing activities and costs may differ by region if fishers target regional stock concentrations. The data were initially subdivided by the county in which fishing trips originate. A comparative analysis indicated no significant county-level differences in production activities.
} 
Table 1

Descriptive statistics for 1993 reef fish vessels

\begin{tabular}{|c|c|c|c|c|c|c|}
\hline & \multicolumn{3}{|c|}{ Per-trip data (1443 obs.) } & \multicolumn{3}{|c|}{ Seasonal data (99 obs.) } \\
\hline & Mean & Std. dev. & Max. & Mean & Std. dev. & Max. \\
\hline $\operatorname{Red}$ snapper $\left(y_{1}\right)$ & 883.97 & 975.69 & $6,314.35$ & $12,884.55$ & $19,432.53$ & $75,458.91$ \\
\hline Other reef fish $\left(y_{2}\right)$ & 713.13 & 1673.26 & $21,161.53$ & $10,394.46$ & $16,883.93$ & $87,025.05$ \\
\hline Non-reef fish $\left(y_{3}\right)$ & 320.53 & $1,067.43$ & $8,762.50$ & $4,671.99$ & $11,248.37$ & $60,056.47$ \\
\hline \multirow[t]{2}{*}{ All fish } & $1,917.64$ & $1,777.53$ & $21,161.53$ & $27,951.00$ & $34,043.48$ & $123,166.91$ \\
\hline & Mean & Std. dev. & Max. & Mean & Std. dev. & Max. \\
\hline Trips & - & - & - & 14.57 & 13.28 & 47 \\
\hline Days at Sea & 3.79 & 2.82 & 14 & 44.19 & 43.38 & 170 \\
\hline Vessel services $\left(x_{1}\right)$ & 178.18 & 163.05 & 910.00 & $2,157.17$ & $2,417.96$ & $12,750.00$ \\
\hline Labor $\left(x_{2}\right)$ & 14.06 & 13.72 & 66.5 & 167.32 & 194.59 & $1,020.00$ \\
\hline Fuel $\left(x_{3}\right)$ & 243.07 & 212.76 & 1200.00 & $3,358.62$ & $4,188.92$ & $24,000.00$ \\
\hline
\end{tabular}

red snapper regulations. The maximum per trip harvest of red snapper is small compared to the maximum per trip harvest of other reef fish. ${ }^{8}$ Evidence of the effects of season closures is also indicated. The maximum seasonal quantity of red snapper is less than the maximum seasonal quantity of other reef fish.

Heterogeneity in vessel activity levels is a conspicuous feature of the data. The seasonal output mix (not reported in Table 1) varies widely across vessels. For example, the ratio of red snapper to other reef fish harvest, $y_{1} / y_{2}$ for the 96 vessels harvesting strictly positive $y_{2}$ has an average value of 10.1 and ranges between 0 and 465.8. Some variation in output mix may be attributed to sitespecific stock variation. Large variation in output mix is also consistent with regulations, in particular, whether vessels possess a 2000 pound per-trip, a 200 pound per-trip, or no permit to harvest red snapper.

The data also exhibit considerable variation in total catch quantities. The maximum total catch per-trip for all species is 11 times larger than the per trip average, and the maximum total catch per season is 4.4 times larger than the seasonal average. Large variation in the number of trips per season further illustrates large variation in the scale of operation. ${ }^{9}$

Table 1 reports the average and standard deviation for the number of trips, days at sea, and the three main inputs used by reef fish vessels; capital services, labor and fuel. The services provided by vessel capital, $x_{1}$, are measured as the vessel length in feet times the number of days that the vessel spent at sea. Labor, $x_{2}$, is measured as the number of crew on board the vessel times days at sea, and fuel, $x_{3}$, is measured in gallons. ${ }^{10}$

\footnotetext{
${ }^{8}$ Nine of the 1443 observations indicated red snapper catches that exceed the 2000 pound limit. Log book data could not be used to penalize operators for exceeding catch limits, and thus violations occurred, although infrequently.

${ }^{9}$ The cost survey data provides an explanation for this heterogeneity; 19 of the 99 vessels in the sample earn part of their annual income in non-fishing activities.

${ }^{10}$ Input use is not proportional to days at sea. Trip length varies and fuel consumption is heaviest during the steam from port to the fishing ground. Furthermore, our data indicate that 30 vessels adjusted crew sizes during the 1993 fishing season. We assume that ice and bait use is proportional to the quantity harvested and that food for the crew is proportional to the labor input.
} 
The price of vessel capital services and fuel are obtained from the cost survey data. The unit price of labor services is difficult to assess in the reef fish fishery because crew are paid using a revenue share system, and because skilled crew members typically earn a wage premium. The cost survey could not be used to obtain an accurate measure of the labor remuneration. We approximate the labor price using average hourly wage for production workers in the northern Gulf region [25]. This yielded a crew-member wage per day of $\$ 93.96$.

For estimation purposes, vessels with incomplete data and vessels that reported less than three trips during 1993 were dropped. The data were examined to identify and remove observations with evidence of reporting error. ${ }^{11}$ This left 71 observations for estimation. Of these, 40 vessels held class 1 red snapper permits and 31 vessels held class 2 permits. Hereafter, vessels with 2000 pound red snapper permits are referred to as class 1 vessels and all other vessels are referred to as class 2 vessels.

An empirical estimate of the DDF is obtained as the solution to the following linear programming problem

$$
\begin{aligned}
& \vec{D}\left(x, y \mid g_{x}, g_{y}\right)=\max \beta \in \mathfrak{R} \\
& \text { s.t } \quad \sum_{k} z^{k} y_{m}^{k}=y_{m}+\beta g_{y, m}, \quad m=1,2, \\
& \sum_{k} z^{k} y_{m}^{k} \geqslant y_{m}+\beta g_{y, m}, \quad m=3, \\
& \sum_{k} z^{k} x_{n}^{k} \leqslant x_{n}-\beta g_{x, n}, \quad n=1,2,3, \\
& \sum_{k} z^{k} \geqslant 1, \\
& z^{k} \geqslant 0, \quad k=1, \ldots, K,
\end{aligned}
$$

where $m$ and $n$ index outputs and inputs, respectively, $z^{k}$ is the intensity variable for vessel $k$, and $K$ is the sample size.

The constraints defining the feasible production set in Eq. (6) impose two key structural restrictions on the harvest technology. First, because reef fish species $y_{1}$ and $y_{2}$ are typically intercepted together, weak output disposibility is assumed for $y_{1}$ and $y_{2}$. This assumption is imposed through the equality constraint $\sum_{k} z^{k} y_{m}^{k}=y_{m}+\beta g_{y, m}$ for $m=1,2$. Under weak output disposibility reducing the quantity of an output, say $y_{1}$ imposes a cost either in terms of forgone production of $y_{2}$ or in terms of increased input requirements [12]. Non-reef fish, $y_{3}$, are harvested independently of reef fish, and thus strong or free output disposibility is assumed for $y_{3}$ (notice the inequality constraint associated with $y_{3}$ ).

The second structural restriction is that the harvest technology exhibits non-decreasing returns to scale (NDRS) over the observed output levels in the 1993 data. The assumption is imposed

\footnotetext{
${ }^{11}$ One vessel reported a per-trip red snapper harvest more than three times the 2000 pound limit (see Table 1). This vessel observation was dropped.
} 


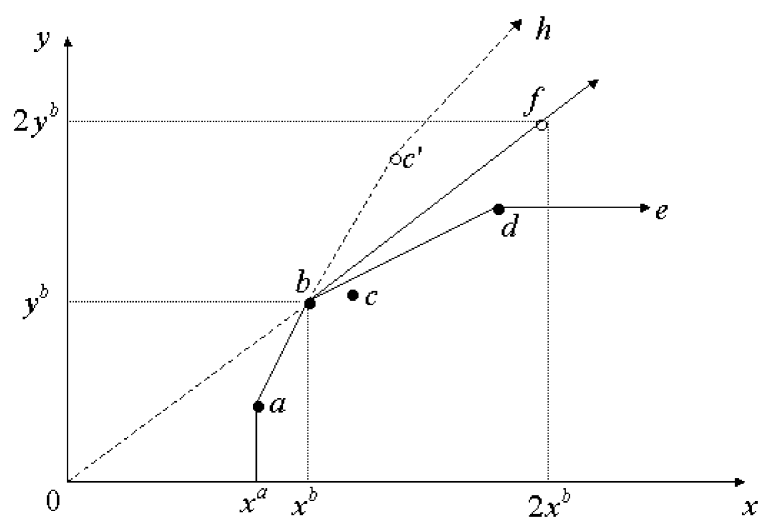

Fig. 1. Effects of per-trip catch limits on data.

through the constraint $\sum_{k} z^{k} \geqslant 1 .^{12}$ Vessels must steam considerable distances from port before fishing begins requiring a minimum threshold input level to harvest a positive quantity of fish. This rules out constant returns to scale (CRS). To understand the assumption of NDRS, it is essential to recognize the role of the controlled access management program on the data generating process. The convex hull of the observed 1993 data characterizes feasible production activities under regulations designed to limit vessel harvest. Switching from controlled access to RB management will likely expand the feasible production set and $T(S, R B) \supseteq T(S, C A)$, where $C A$ is "controlled access" management. Consequently, basing our analysis on the convex hull of the 1993 data will potentially underestimate production possibilities available under RB management.

Fig. 1 illustrates this phenomenon with hypothetical data for four vessels operating under controlled access regulations. For simplicity, a single input and a single output are shown. Vessel $a$ employs $x^{a}$ and harvests $y^{a}$ and similarly for vessels $b, \ldots, d$. Under CRS, an estimate of the CRS feasible set is obtained as the canonical hull of the observed data. In Fig. 1, the boundary of the feasible set is a ray extending from the origin through $\left(x^{b}, y^{b}\right)$. Under the assumption of variable returns to scale (VRS), the boundary of the feasible set is $x^{a} a b d e$ and vessels $a, b$, and $d$ are considered technically efficient. Activity $d$ exhibits a low output/input ratio relative to $b$, which is consistent with a region of the technology that exhibits decreasing returns to scale. Importantly however, the low output/input ratio at $d$ is also consistent with a per-trip catch limit policy, which is more likely to bind for large vessels. The activity level at $d$ exhibits ostensible decreasing returns to scale. It is important that the relatively low output/input ratio at $d$ not be interpreted as a region of true decreasing returns to scale unless there is reason to believe that the (unregulated) harvest technology exhibits this property.

Discussions with industry indicate that some vessels were not severely constrained by the pertrip catch limit. For example, suppose vessel $b$ holds a 2000 pound per trip red snapper permit and typically harvests less than 2000 pounds per trip. Assuming the per trip harvest regulation did not

\footnotetext{
${ }^{12}$ Variable returns to scale is imposed by replacing the constraint $\sum_{k} z^{k} \geqslant 1$ with $\sum_{k} z^{k}=1$. These constraints are dropped under the assumption of a constant returns to scale technology.
} 
bind for vessel $b,\left(x^{b}, y^{b}\right)$ is feasible and technically efficient. Furthermore, activity $\left(x^{b}, y^{b}\right)$ should be replicatable simply by increasing the number of fishing trips in a season. This implies $\left(2 x^{b}, 2 y^{b}\right)$, point $f$ in Fig. 1 should also be feasible and technically efficient in the absence of controlled access regulations.

Based on prior knowledge of the data generating process, and on the assumption that some vessels in the 1993 data are unconstrained under per-trip catch limits, we assume that the harvest technology exhibits NDRS over the range of harvest levels observed in 1993. The frontier that is attainable under RB management can be approximated by the intersection of the convex and canonical hulls of the 1993 data. In Fig. 1, the feasible set under NDRS is defined by the segment $x^{a} a b$ and then along a ray that extends from $b$ through $f$.

Note that the slope of the ray $b f$ may underestimate the feasible output/input ratio for unconstrained vessels, particularly larger ones. On a typical fishing trip, output per unit of input is zero during the steam from port to a chosen fishing site. Thereafter, the quantity harvested per unit of input is positive. It is possible that in the absence of a per-trip catch limits vessel $c$ would have obtained the activity level $\left(x^{c^{\prime}}, y^{c^{\prime}}\right)$ at point $c^{\prime}$. That is, it is conceivable that vessel $c$ could have allocated additional inputs during actual fishing operations equal to $x^{c^{\prime}}-x^{c}$ and obtained additional output $y^{c^{\prime}}-y^{c}$. Because $\left(x^{c^{\prime}}, y^{c^{\prime}}\right)$ is unobserved in the 1993 data, it is possible that the RB-regime frontier will be underestimated. ${ }^{13}$

\subsection{Harvesting efficiency under controlled access management}

This section examines harvesting technical efficiency, cost and scale efficiency for seasonal activity levels of the 1993 sample vessels. ${ }^{14}$ Table 2 reports the sample average and standard deviation for four measures of harvesting performance (efficiency). The measures are calculated using GAUSS software; the program is available upon request from the authors. For comparison, average values and standard deviations are reported for the full sample, and for classes 1 and 2 vessels.

Columns 1 and 2 of Table 2 report output-oriented efficiency measures. For each vessel, the DDF is estimated with directional vector $g_{x}=0_{n}$ and $g_{y}=\left(y_{1}, 0,0\right)$. In this case the DDF yields the maximum feasible translation (expansion) of observed red snapper harvest, $y_{1}$, holding inputs fixed, and maintaining the vessel's observed harvest of $y_{2}$ and $y_{3}$. Column 1 reports the ratio of the observed $y_{1}$ to the frontier quantity, calculated as $y_{1}+\vec{D}\left(x, y \mid 0_{n}, g_{y}\right) y_{1}$. The values on Column 1 are thus interpreted as the portion of the frontier red snapper harvested by the sample vessel.

The full sample average value is 0.70 with standard deviation 0.23 ; on average vessels harvested $70 \%$ of the frontier red snapper output. A comparison across vessel classes finds that, on average, class 1 vessels harvested $58 \%$ of the frontier $y_{1}$ whereas class 2 vessels harvested $78 \%$ of the frontier $y_{1}$. The average performance of class 2 vessels is high in part because ten class 2 vessels did not harvest red snapper. These vessels obtain a DDF value of zero with the directional vector

\footnotetext{
${ }^{13}$ We would like to thank Jay Coggins for this insight. An anonymous referee suggests that information about $c^{\prime}$ could be obtained by distinguishing inputs used during steaming from inputs used during fishing. Our reef fish data does not allow an accurate breakdown of steaming versus searching time, and this approach could not be implemented.

${ }^{14} \mathrm{~A}$ seasonal level analysis simplifies the characterization of vessels activity levels expected under RB management. See also [9].
} 
Table 2

Efficiency of 1993 sample vessels

\begin{tabular}{lcccc}
\hline & 1 & 2 & 3 & 4 \\
& \multicolumn{1}{c}{$\frac{y_{1}}{y_{1}+\vec{D}\left(x, y \mid 0_{n}, g_{y}\right) y_{1}}$} & $\frac{y_{2}}{y_{2}+\vec{D}\left(x, y \mid 0_{n}, g_{y}\right) y_{2}}$ & $O(y, x, w)$ & $A E(x, y, w)$ \\
& $g_{y}=\left(y_{1}, 0,0\right)$ & $g_{y}=\left(0, y_{2}, 0\right)$ & \\
\hline $\begin{array}{l}\text { All vessels } \\
\text { (71 obs.) }\end{array}$ & 0.70 & 0.65 & 0.65 & 0.86 \\
Class 1 vessels & $(0.23)$ & $(0.21)$ & $(0.25)$ & $(0.14)$ \\
$(40$ obs.) & 0.58 & 0.59 & 0.61 & 0.85 \\
Class 2 vessels & $(0.17)$ & $(0.18)$ & $(0.21)$ & $(0.13)$ \\
(31 obs.) & 0.85 & 0.69 & 0.71 & 0.88 \\
\hline
\end{tabular}

Class 1 vessels are those in possession of 2,000 pound per trip red snapper permit, Class 2 vessels refer to all other vessels. Standard deviations are in parentheses.

$g_{y}=\left(y_{1}, 0,0\right)$ and are thus considered technically efficient (all class 1 vessels harvested red snapper). The ratio of actual to frontier red snapper for the 21 class 2 vessels harvesting strictly positive $y_{1}$ is 0.78 with standard deviation 0.23 .

Conditional on observed values for $x, y_{2}$, and $y_{3}$, class 2 vessels harvested a larger portion of the frontier red snapper than class 1 vessels. This difference is supported statistically. A Wilcoxon-Mann-Whitney nonparametric test of the null hypothesis of common performance for classes 1 and 2 vessels (harvesting strictly positive $y_{1}$ ) is rejected at the $99.8 \%$ confidence level. This result is consistent with expectations once one recognizes that class 1 vessels harvested on average 30,000 pounds of red snapper under distorting regulations whereas, class 2 vessels harvested on average roughly 1000 pounds of red snapper under distorting regulations.

Column 2 reports the results for other reef fish, $y_{2}$. The DDF was calculated with directional vector $g_{x}=0_{n}$ and $g_{y}=\left(0, y_{2}, 0\right)$. In this case, the DDF measures the maximal translation of observed $y_{2}$ to the frontier, holding inputs fixed, and maintaining the vessel's observed harvest of $y_{1}$ and $y_{3}$ (all but 2 vessels harvested positive $y_{2}$ ). As above, column 2 reports the ratio of observed and frontier quantities of $y_{2}$, and is interpreted as the proportion of the frontier $y_{2}$ harvested by the sample vessels. The full sample average is 0.65 with standard deviation 0.21 . The average for class 1 vessels is 0.59 , which is less than the average for class 2 vessels $(0.69)$ indicating that class 2 vessels harvested a larger portion of the frontier $y_{2}$ than class 1 vessels; a Wilcoxon-MannWhitney test of the null hypothesis of common performance is rejected at the $98.3 \%$ confidence level.

Column 3 of Table 2 reports the ratio of frontier and observed costs, $O(x, y, w)$. Results indicate that frontier cost is on average $65 \%$ of observed costs. A comparison across vessel classes indicates that, on average, class 1 vessels were less cost efficient than class 2 vessels. However, differences in the cost efficiency across vessel classes are not significant at conventional levels; a test of the null hypothesis of common cost efficiency is rejected at the $86.2 \%$ confidence level. Column 4 summarizes input-allocative efficiency. The sample average is 0.86 with standard deviation of 0.14. Differences across vessel classes are small. 
Table 3

Scale and input-oriented technical efficiency for 1993 sample vessels

\begin{tabular}{|c|c|c|c|c|c|c|c|}
\hline & \multirow{4}{*}{$\begin{array}{l}\text { Full sample } \\
\overrightarrow{S E}(x, y) \\
{\left[D_{i}(x, y)^{-1}\right]^{\mathrm{a}}}\end{array}$} & \multicolumn{6}{|c|}{ Breakdown by scale of operation } \\
\hline & & \multicolumn{2}{|c|}{ Increasing returns } & \multicolumn{2}{|c|}{ Constant returns } & \multicolumn{2}{|c|}{ Decreasing returns } \\
\hline & & Vessels & $\overrightarrow{S E}(x, y)$ & Vessels & $\overrightarrow{S E}(x, y)$ & Vessels & $\overrightarrow{S E}(x, y)$ \\
\hline & & [Length] & {$\left[D_{i}(x, y)^{-1}\right]^{\mathrm{a}}$} & [Length] & {$\left[D_{i}(x, y)^{-1}\right]^{\mathrm{a}}$} & [Length] & {$\left[D_{i}(x, y)^{-1}\right]^{\mathrm{a}}$} \\
\hline $\begin{array}{l}\text { All vessels } \\
\text { ( } 71 \text { obs.) }\end{array}$ & $\begin{array}{l}0.79^{\mathrm{b}} \\
{\left[0.81^{\mathrm{b}}\right]}\end{array}$ & $\begin{array}{l}23 \\
{\left[35.8^{\mathrm{b}}\right]}\end{array}$ & $\begin{array}{l}0.57^{\mathrm{b}} \\
{\left[0.66^{\mathrm{b}}\right]}\end{array}$ & $\begin{array}{l}20 \\
{\left[43.3^{\mathrm{b}}\right]}\end{array}$ & $\begin{array}{l}1^{\mathrm{b}} \\
{\left[0.95^{\mathrm{b}}\right]}\end{array}$ & $\begin{array}{l}28 \\
{\left[51.9^{\mathrm{b}}\right]}\end{array}$ & $\begin{array}{l}0.83^{\mathrm{b}} \\
{\left[0.83^{\mathrm{b}}\right]}\end{array}$ \\
\hline $\begin{array}{l}\text { Class } 1 \\
\text { (40 obs.) }\end{array}$ & $\begin{array}{l}0.90 \\
{[0.82]}\end{array}$ & $\begin{array}{l}3 \\
{[42.3]}\end{array}$ & $\begin{array}{l}0.97 \\
{[0.42]}\end{array}$ & $\begin{array}{l}12 \\
{[41.5]}\end{array}$ & $\begin{array}{l}1 \\
{[0.91]}\end{array}$ & $\begin{array}{l}25 \\
{[52.7]}\end{array}$ & $\begin{array}{l}0.84 \\
{[0.82]}\end{array}$ \\
\hline $\begin{array}{l}\text { Class } 2 \\
\text { (31 obs.) }\end{array}$ & $\begin{array}{l}0.66 \\
{[0.79]}\end{array}$ & $\begin{array}{l}20 \\
{[34.9]}\end{array}$ & $\begin{array}{l}0.51 \\
{[0.70]}\end{array}$ & $\begin{array}{l}8 \\
{[45.9]}\end{array}$ & $\begin{array}{l}1 \\
{[1.00]}\end{array}$ & $\begin{array}{l}3 \\
{[45.0]}\end{array}$ & $\begin{array}{l}0.80 \\
{[0.86]}\end{array}$ \\
\hline
\end{tabular}

${ }^{\mathrm{a}} \mathrm{DDF}$ values are calculated relative to a variable returns technology.

${ }^{\mathrm{b}}$ Reported values are averages.

Table 3 reports the average values of the scale efficiency measure, $\overrightarrow{S E}(x, y)$, and the FarrellDebreu measure of input-oriented technical efficiency, $D_{i}(x, y)^{-1}=1-\vec{D}\left(x, y \mid g_{n}, 0_{m}\right)$, where $g_{n}=$ $x$. The Farrell-Debreu measure is evaluated relative to a VRS technology. Conditional on the output vector, $y$, and the observed input mix, $\overrightarrow{S E}(x, y)$ measures the radial distance between the VRS and CRS input frontier, whereas $D_{i}(x, y)^{-1}$ measures the distance of the observed input bundle to the VRS frontier. The two measures thus decompose the input-oriented inefficiency into a scale component and a component due to pure technical inefficiency. Disaggregated results for vessels found operating under increasing, constant and decreasing returns to scale, along with average vessel length are reported in Table 3 to assist in interpreting the results.

The full sample average value of $\overrightarrow{S E}(x, y)$ is 0.79 . Of the 71 vessels, $23(32.4 \%)$ are found to operate in a region of increasing returns to scale (IRS), $20(28.2 \%)$ operate scale efficiently and 28 $(39.4 \%)$ operate in a region of decreasing returns to scale (DRS). The average value of $\overrightarrow{S E}(x, y)$ is 0.57 for vessels operating under IRS and 0.83 for vessels operating under DRS. The full sample average value of $D_{i}(x, y)^{-1}$ is 0.81 . No significant differences in input-oriented technical inefficiency are indicated across vessel classes.

Vessels that are scale efficient tend also to be technically efficient. A comparison of vessel size indicates a pattern where vessels operating under IRS tend to be smaller and less technically efficient. Vessels operating under DRS tend to be larger; however, this finding must be interpreted cautiously given the regulations under which the data are generated. Following Banker [2], statistically significant decreasing returns are indicated at the $95.1 \%$ confidence level. Whether this finding is evidence of true decreasing returns, ${ }^{15}$ or ostensible decreasing returns due to the effects of per-trip catch limits is difficult to know.

\footnotetext{
${ }^{15} \mathrm{An}$ anonymous referee points out that congregation of fish and local depletion of fish stocks, particularly those stocks closer to shore, could cause true decreasing returns to scale for a harvesting technology.
} 
Scale inefficiency among class 1 vessels is due primarily to operation under (ostensible) DRS. Of the 40 class 1 vessels, 25, averaging 52.7 feet in length, operate under decreasing returns. The average Farrell-Debreu measure is 0.82 . Scale efficient class 1 vessels average 41.5 feet in length. Only 3 class 1 vessels are found to operate under increasing returns.

Scale inefficiency among class 2 vessels is due primarily to operation under IRS. These vessels tend to be smaller; $34.9 \mathrm{ft}$ in length on average. Further investigation reveals that class 2 vessels operating under IRS spent on average 14.9 days at sea whereas vessels found operating scale efficiently (full sample) spent an average of 46.9 days at sea in 1993.

To summarize, the analysis of harvesting efficiency in the 1993 data is consistent with (but does not confirm) the hypothesized effects of the controlled access regulatory environment. Output-oriented technical inefficiency is found to be concentrated among class 1 vessels and in red snapper harvesting activities, despite the fact that the initial allocation of class 1 endorsement permits went to vessels that could demonstrate an historical record of high catch rates; i.e., class 1 vessels are more likely to be experienced and successful operators. Smaller class 2 vessels are found to be scale inefficient due to operation in a region of increasing returns. Scale inefficiency due to ostensible DRS is indicated for larger class 1 vessels, although the interpretation of this finding is complicated given the regulations under which the data are generated.

\subsection{Net revenue under $R B$ management}

We begin by predicting the vessel harvesting practices under a system of tradable harvest permits for all reef fish species, and under long run equilibrium. For simplicity we assume all vessels harvest the same output mix. Necessary conditions for equilibrium are: (1) the marginal harvesting cost be equal across outputs and across active vessels; and (2) no active vessel can profitably exit or enter the fishery. The first condition ensures that there are no (short-run) gains from redistributing the catch among active vessels. The second condition ensures that the RB fleet is in long run equilibrium.

Consider first the output mix under RB management. Reef fish vessels must make costly gear modifications to harvest non-reef fish, $y_{3}$. These costs represent a superadditive fixed cost. No evidence is indicated to suggest cost complementarity between reef and non reef fish, and thus harvesting $y_{3}>0$ creates diseconomies of scope [3]. Cost complementarity between red snapper and other reef fish species is a natural consequence when species are intercepted by the same gear on the same trip. Vessels that incur gear modification costs to harvest non-reef fish or added costs to specialize in harvesting a single species of reef fish will not minimize multiproduct harvest costs. We conclude that the output bundle under RB management will be comprised of a mix of red snapper and other reef fish species, and zero quantity of $y_{3}$. Predicting the precise mix of red snapper and other reef fish is a complex matter that will not be attempted. For convenience we set the individual vessel output mix equal to the aggregate output mix harvested in the reef fish fishery in 1993, and note that additional gains from output adjustments may be available under tradable harvest permits. ${ }^{16}$

\footnotetext{
${ }^{16}$ See $[23,22,28]$ for additional discussion of equilibrium fleet structure in multi-species fisheries under RB management.
} 
Consider next the scale of production for a vessel of fixed size operating over a full harvest season. Vessel capital services, i.e., vessel length times days at sea, are constrained by the number of days in a year and weather conditions. Discussions with industry and evidence from the log book data indicate that a 35 foot vessel can spend roughly 100 days at sea in a typical year. Because larger vessels can fish in more severe weather, sources indicate that a vessel of length 45 , 55 and $65 \mathrm{ft}$ can spend roughly 110, 120, 130, days at sea, respectively, in a typical year.

Reef fish vessel owners incur fixed and avoidable annual operating costs to secure the services of a vessel. These costs include state and federal license fees, docking fees, office staffing and equipment costs. In addition, vessels must occasionally undertake costly hull and engine overhauls, and replace damaged or worn equipment. The presence of fixed annual costs, and NDRS over the range of output levels observed in our data, imply that ray average cost (RAC) will decline and attain a minimum when the inputs are allocatively efficient and when all available vessel services are utilized, i.e., when a vessel spends the maximal days at sea. Because capital services are constrained for a vessel of fixed size, further increases in output would require increases in the quantity of fuel and/or labor per-unit of vessel capital, resulting in input-allocative inefficiency. It can be shown that the output that minimizes global RAC maximizes the value of a vessel operation, and thus maximizes the residual return to the tradable harvest permits. ${ }^{17} \mathrm{We}$ approximate the global RAC minimizing output quantity by fixing the output mix as above and expanding the scale of production until capital services from a vessel of fixed size are fully utilized. The long run fleet structure is then obtained as the minimum number of vessels capable of harvesting the aggregate reef fish catch.

Equilibrium output and fleet structure under RB management may also be characterized using virtual prices, and the concept of capacity utilization. The RB output vector is the long run supply at output prices equal to virtual prices, defined as the dockside prices less the quota lease rates [22]. At this output level and virtual prices, the shadow price of vessel capital will equal to the market price of capital. Our analysis does not identify the optimal output mix under RB management, however, the assumed RB output corresponds to the ray full capacity output as defined in [19].

\subsection{Rights based vessel activity and fleet harvesting costs}

The section predicts $\mathrm{RB}$ harvest activity for four representative vessel sizes, indexed by $j=$ $1, \ldots, 4$. Vessel 1 is 35 feet in length, vessels 2, 3, and 4 are, respectively, 45, 55, and 65 feet in length. ${ }^{18}$ The following four step procedure is used to identify the RB vessel activity levels.

Step 1: The objective of the first step is to identify the allocatively efficient input mix required to harvest an output vector that will be denoted $y^{j, 1}$ for vessel $j .{ }^{19}$ Output $y^{j, 1}$ is comprised of positive

\footnotetext{
${ }^{17}$ Let $y^{*}$ denote the annual output that minimizes global RAC. Consider an increase in output from $y^{*}$ to $v y^{*}$, where $v>1$. Revenues increase by a factor of $v$. But if $y^{*}$ minimizes RAC, $C\left(v y^{*}\right)>v C\left(y^{*}\right)$ which implies $p v y^{*}-C\left(v y^{*}\right)<$ $p y^{*}-C\left(y^{*}\right)$. A similar argument can be made for the case where $v<1$.

${ }^{18}$ There are only 7 sample vessels less than $35 \mathrm{ft}$ in length, and reliable estimates of fixed costs could not be obtained. The data contained 19 vessels $30-40 \mathrm{ft}$ in length, 15 vessels 40-50 ft in length, 12 vessels 50-60 ft in length and 12 vessels greater than $60 \mathrm{ft}$ in length.

${ }^{19}$ The output $y^{j, 1}$ is selected to ensure that it lies in the interior of the feasible production set. The intensity variables $z_{k}$ for the simulated vessels were checked to ensure that they did not influence the estimate of the feasible set.
} 
quantities of red snapper and other reef fish and zero quantity of non-reef fish. The ratio of red snapper and other reef fish is set equal to the ratio of the red snapper TAC and aggregate catch of other reef fish in 1993. The allocatively efficient input vector is identified using sample average input prices, and is denoted $x^{j, 1}$.

Step 2: The objective of the second step is to identify the frontier output that can be harvested using inputs $x^{j, 1} \cdot{ }^{20}$ To accomplish this step we estimate $\vec{D}\left(x^{j, 1}, y^{j, 1} \mid 0, y^{j, 1}\right)$ and calculate the frontier output $y^{j, 2}=y^{j, 1}\left(1+\vec{D}\left(x^{j, 1}, y^{j, 1} \mid 0, y^{j, 1}\right)\right)$. This yields a technical, input-allocative, and scale efficient activity, $\left(x^{j, 2}, y^{j, 2}\right)$.

Step 3: The objective of step 3 is to estimate the RB harvest costs associated with activity $\left(x^{j, 2}, y^{j, 2}\right)$. For this purpose note that inefficient harvest practices will in general be caused by external factors that are outside of the control of a firm, such as distorting regulations and depleted stocks, and internal factors, such as errors in judgement by the vessel captain and crew, or managerial inefficiency caused by misaligned worker incentives and information asymmetry. ${ }^{21}$ Command and control regulations intended to reduce fishing mortality are eliminated under RB management but inefficiency from internal sources are expected to persist. For example, cost efficiency under RB management may be constrained by heterogeneity in fishing skill [1].

An unbiased estimate of harvest costs under RB management must be purged of inefficiency caused by distorting regulations but allow for inefficiency caused by internal factors. Furthermore, to allow for the possibility that cost efficiency is systematically related to the output mix, an estimate of internal cost efficiency from vessels harvesting both red snapper and other reef fish is preferred. To obtain such an estimate we rely on the level of cost efficiency attained by vessels with 2000 pound per trip red snapper permits. While these vessels faced pertrip catch limits they provide a reasonable (best available) estimate of the internal harvesting efficiency that will prevail under RB management.

Let $\hat{O}^{\mathrm{RB}}$ denote an estimate of internal cost efficiency, reflecting either pure technical, inputallocative or scale inefficiency, that prevails under RB management. Class 1 cost efficiency scores are viewed as a random sample of identically distributed random variables drawn from a common distribution. A naive bootstrap procedure is used to estimate percentile values of the cost efficiency distribution. Fig. 2 depicts the estimated cost efficiency scores for all sample vessels and reports the 50'th through 90'th percentile bootstrap values attained by class 1 vessels.

Manipulation of Eq. (4) obtains the following estimate of harvesting costs under RB management:

$$
C^{\mathrm{RB}}\left(y^{j, 2}, \bar{w}\right)=\frac{\sum_{i} \bar{w}_{i} x^{j, 2}}{\hat{O}^{\mathrm{RB}}}, \quad j=1, \ldots, 4 .
$$

Step 4: The objective of the final step is to scale the vessel activity $\left(x^{j, 2}, y^{j, 2}\right)$ and associated harvest costs $C^{\mathrm{RB}}\left(y^{j, 2}, \bar{w}\right)$ to the level that is expected in the absence of periodic seasonal closures. A scaling factor $\lambda^{j}$ is calculated such that the quantity of vessel capital services is equal to the maximal capital services that are available over a 365 day season. For each vessel class the scale

\footnotetext{
${ }^{20}$ Notice that under a constant returns to scale harvest technology, step 2 is unnecessary since $\left(x^{j, 1}, y^{j, 1}\right)$ would already lie on the scale efficient frontier. Under a non-decreasing returns to scale technology an output expansion will be possible in general.

${ }^{21}$ See [13] for additional discussion. The possibility that weak or misaligned managerial incentives cause productive inefficiency underlies the concept of X-inefficiency (see Leibenstein [18]).
} 


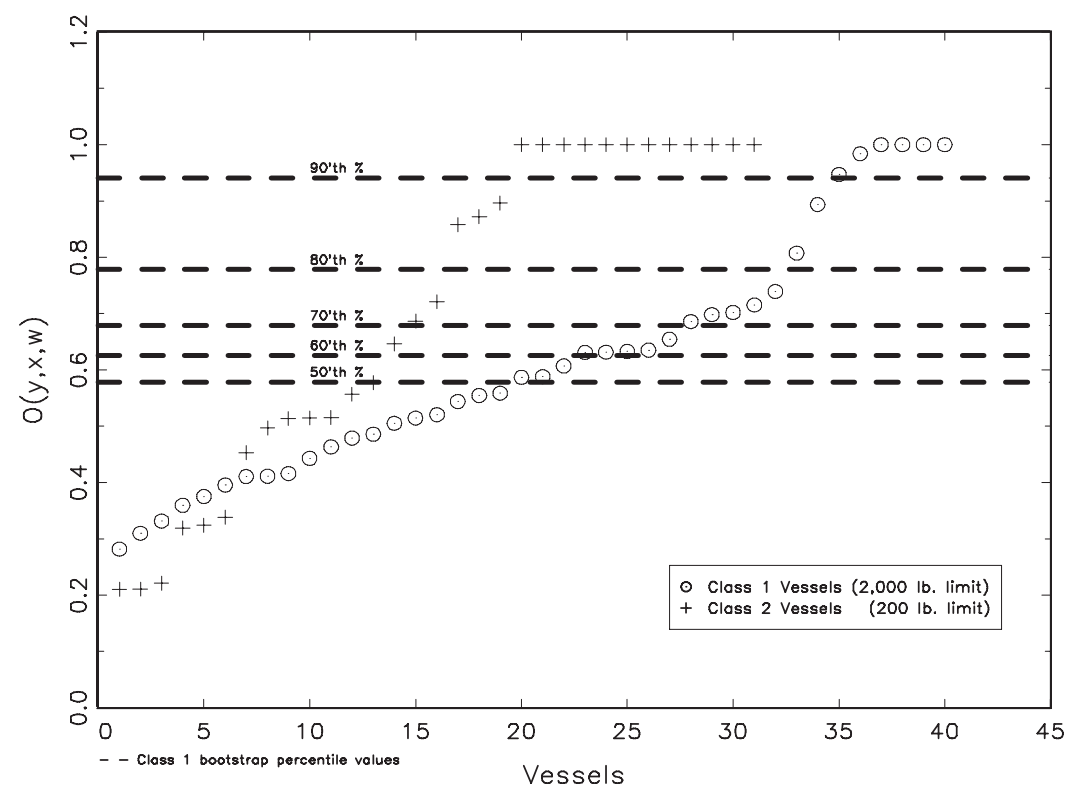

Fig. 2. Cost efficiency estimates for sample vessels.

Table 4

Predicted vessel activity, fixed and average cost under RB management

\begin{tabular}{|c|c|c|c|c|c|c|c|}
\hline \multirow{2}{*}{$\begin{array}{l}\text { Vessel length } \\
\text { (ft) }\end{array}$} & \multicolumn{2}{|c|}{ Harvest quantity } & \multicolumn{5}{|c|}{ Fixed and average cost for RB vessels } \\
\hline & $\begin{array}{l}\text { Red } \\
\text { Snapper }\end{array}$ & $\begin{array}{l}\text { Other reef } \\
\text { fish }\end{array}$ & $\mathrm{FC}$ & $\mathrm{VC}$ & $\begin{array}{l}\text { RAC } \\
\hat{O}^{\mathrm{RB}}=0.627\end{array}$ & $\begin{array}{l}\mathrm{RAC} \\
\hat{O}^{\mathrm{RB}}=0.679\end{array}$ & $\begin{array}{l}\mathrm{RAC} \\
\hat{O}^{\mathrm{RB}}=0.780\end{array}$ \\
\hline 35 & 48,825 & 101,343 & 9,017 & 25,421 & 0.330 & 0.309 & 0.277 \\
\hline 45 & 69,053 & 143,328 & 11,535 & 35,952 & 0.324 & 0.304 & 0.271 \\
\hline 55 & 92,070 & 191,104 & 14,680 & 47,936 & 0.322 & 0.301 & 0.269 \\
\hline 65 & 117,878 & 244,671 & 19,478 & 61,373 & 0.324 & 0.303 & 0.271 \\
\hline
\end{tabular}

$\mathrm{FC}$ is annual fixed cost, $\mathrm{VC}$ is variable cost, RAC is ray average cost.

factor $\lambda^{j}$ is used to obtain the seasonal activity level $\lambda^{j}\left(x^{j, 2}, y^{j, 2}\right)$. Seasonal harvest costs are then obtained as $\lambda^{j} C^{\mathrm{RB}}\left(y^{j, 2}, \bar{w}\right)$.

Table 4 reports the predicted RB-regime output of red snapper and other reef fish, annual fixed costs, and RAC for four vessel sizes. The RAC estimates, the last three columns of Table 3, assume three levels of (internal) cost inefficiency. The highest reported RAC assumes that the RB fleet will achieve the 60th percentile value of cost efficiency obtained by class 1 vessels in 1993; $\hat{O}^{\mathrm{RB}}=0.627$. The last two columns in Table 4 report RAC under the $70^{\prime}$ th $\left(\hat{O}^{\mathrm{RB}}=0.679\right)$ and 80 'th $\left(\hat{O}^{\mathrm{RB}}=0.780\right)$ percentile values.

From Table 4, predicted output increases with vessel size as expected and 55 foot vessels attain the lowest RAC, although the difference across vessel sizes is less than 1 cent per pound. RAC for 
35 foot vessels is $\$ 0.006-\$ 0.008$ per pound higher than for larger vessel. The analysis thus predicts that the RB fleet will be comprised of vessels that exceed $35 \mathrm{ft}$ in length.

Suppose that the RB fleet attains the 70th percentile level of cost efficiency and is comprised of 45-65 foot vessels. The equilibrium number of vessels is then predicted by dividing the aggregate catch of reef fish by the RB output quantities. This calculation indicates that the number of active vessels under RB management will be 29 if comprised of 65 foot boats and 70 if comprised of 35 foot boats. Put another way, 29-70 vessels harvesting at ray capacity output levels are capable of harvesting the entire 1993 reef fish catch.

Assuming the 70 'th percentile level of cost efficiency, the RAC for the predicted RB fleet is, on average, $\$ 0.303$. The total cost of harvesting the TAC of red snapper and aggregate catch of other reef fish is estimated to be $\$ 3.166 \mathrm{~m}$. If the RB fleet attains the $60^{\prime}$ th ( $80^{\prime}$ th) percentile level of cost efficiency the RAC is predicted to be on average $\$ .323$ (\$.270) and the total cost incurred by the $\mathrm{RB}$ fleet is $\$ 3.384 \mathrm{~m}(\$ 2.828 \mathrm{~m})$.

Under the controlled access management program, the RAC for the 71 vessels in our sample is $\$ 1.043$. Two factors influencing this sample average must be considered. First, 41 sampled vessels harvested non-reef fish species in 1993. To control for the influence of non-reef fish harvest costs we approximate costs associated with reef fish fishing as the total cost weighted by the proportion of reef fish that each vessel harvested. This correction increases the sample RAC to \$1.089. A second consideration is that some vessels in the 1993 sample are part time fishers who take a relatively small number of trips per year. The sample average RAC for full time reef fish vessels is $\$ 1.030$. We correct for non-reef fish harvest as above to obtain an estimate of RAC of $\$ 1.074$.

Using \$1.074 as the actual RAC incurred by the 1993 fleet, the actual costs to harvest the aggregate reef fish catch in 1993 under the controlled access management policy is estimated to be $\$ 11.244 \mathrm{~m}$. The predicted cost savings from adopting tradable harvest permits is thus estimated to be $\$ 8.078 \mathrm{~m}$ if vessels attain the 70th percentile level of internal cost efficiency. If vessels attain the 60th (80th) percentile level of cost efficiency, the harvest cost saving is estimated to be $\$ 7.860 \mathrm{~m}$ $(\$ 8.416 \mathrm{~m})$.

\subsubsection{RB red snapper revenues}

An estimate of potential revenue gains under RB management is obtained by predicting the red snapper dockside price in the absence of seasonal closures. Data on annual average dockside prices for red snapper were collected from the National Marine Fisheries Service for 1962-1999. These data are used in the following regression model, ${ }^{22}$

$$
p_{t}=\alpha_{0}+\alpha_{1} p_{t-1}+\alpha_{2} \tau+\alpha_{3} D_{t}^{\mathrm{TAC}} T A C_{t}+\alpha_{4} \theta_{t}+\varepsilon_{t} .
$$

The dependent variable, $p_{t}$, is the real annual average dockside price for red snapper in year $t ; p_{t-1}$ is the one-period lagged price and $\tau$ is a trend variable. The commercial red snapper harvest was managed under a TAC policy from 1990-1999 and can be assumed exogenous during this period. $D_{t}^{\mathrm{TAC}}$ denotes indicator variable set equal to 0 for $t<1990$ and 1 for

\footnotetext{
${ }^{22} \mathrm{An}$ alternative approach for estimating the equilibrium red snapper price is to specify and estimate a structural model of red snapper supply and consumer demand. Data limitations, and complications that arise in modeling supply under a complex regulatory environment precluded such an approach.
} 
Table 5

Parameter estimates for dockside price model

\begin{tabular}{llcc}
\hline Variable & Parameter & Estimate & Std. error \\
\hline constant & $\alpha_{0}$ & -0.201 & 0.148 \\
$p_{t-1}$ & $\alpha_{1}$ & $0.499^{* *}$ & 0.089 \\
$\tau$ (trend) & $\alpha_{2}$ & $0.033^{* *}$ & 0.007 \\
$D_{t}^{\text {TAC }} T A C_{t}$ & $\alpha_{3}$ & $-0.056^{*}$ & 0.032 \\
$\theta_{t}$ (season length) & $\alpha_{4}$ & $0.782^{* *}$ & 0.158 \\
\hline
\end{tabular}

There are 37 observations. A single [double] asterisk indicates parameter is significantly different from zero at or above the 90 [99] percent confidence level.

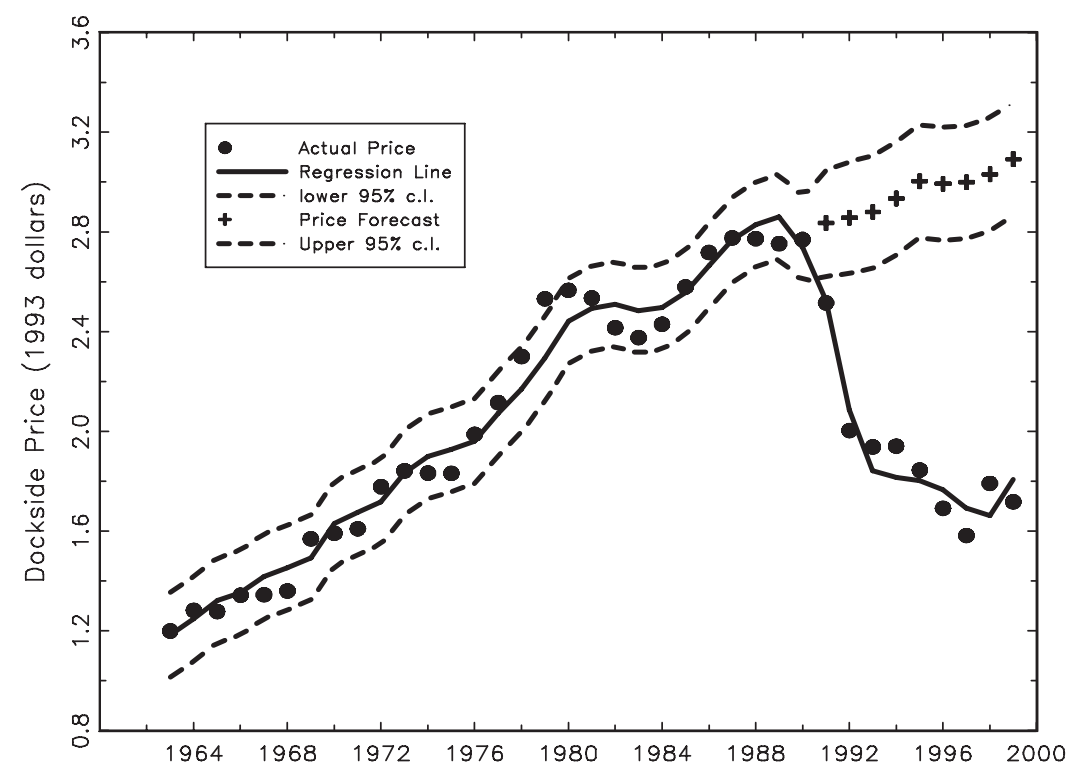

Fig. 3. Annual average dockside prices for Red Snapper in the Gulf of Mexico.

$t \geqslant 1990$. This variable is then interacted with the TAC. $\theta_{t}$ measures the portion of the year that the red snapper fishery remained open in year $t$. The disturbance term $\varepsilon_{t}$ is assumed to have zero mean and finite variance.

The model in Eq. (8) was estimated using ordinary least-squares regression. A Durbin- $h$ test indicated first-order serially correlated disturbances (at the $96.7 \%$ confidence level). The model was reestimated using the iterative feasible generalized least-squares (Cochrane-Orcutt) procedure. Parameter estimates and standard errors from this procedure are reported in Table 5.

All slope parameters are statistically different from zero at or above the $90 \%$ confidence level. Parameter signs are as expected. A larger aggregate harvest leads to a lower dockside price $\left(\alpha_{3}<0\right)$ and increases in the season length raise the average dockside price $\left(\alpha_{4}>0\right)$. The adjusted $R^{2}$ statistic is 0.959 . 
A price forecast and variance function is calculated for the period 1990-1999 using the fitted parameters from Table 5 and by setting $\theta_{t}=1$. The fitted regression line, price forecast, and $95 \%$ confidence interval for the predicted price are plotted in Fig. 3.

The average dockside price for red snapper in 1993 with season length restricted to 95 days was $\$ 1.94$. The predicted price with season length set at 365 days is $\$ 2.88$ with a $95 \%$ confidence interval $(\$ 2.65, \$ 3.11)$. The total red snapper catch in 1993 was $3.405 \mathrm{~m}$ pounds. Red snapper revenues absent a seasonal closure are estimated to be $\$ 9.805 \mathrm{~m}$ with $95 \%$ confidence interval $[\$ 9.036 \mathrm{~m}, \$ 10.575 \mathrm{~m}]$. The actual 1993 revenue was $\$ 6.598 \mathrm{~m}$ indicating potential revenue gains under RB management of $\$ 3.208 \mathrm{~m}$ with a $95 \%$ confidence interval $[\$ 2.438 \mathrm{~m}, \$ 3.977 \mathrm{~m}]$.

\section{Sensitivity analysis and institutional considerations}

Combined revenue gains and cost savings in 1993 are estimated to be $\$ 11.284 \mathrm{~m}$. This section assesses the sensitivity of this estimate to data errors, model assumptions and estimation methods, and discusses other institutional factors that may affect or impede the realization of the estimated benefits.

\subsection{Sensitivity analysis}

Data envelopment analysis was used to estimate vessel activity and cost savings under RB management. This technique uses non-parametric linear programming to estimate a piece-wise linear harvest frontier enveloping the observed 1993 data. All deviations from the frontier are attributed to production inefficiency. The possible influence of data measurement errors and other noise is not explicitly accounted for during estimation (Färe et al. [11] discuss further strengths and weaknesses of data envelopment analysis in fisheries).

The sensitivity of the cost savings estimate to data errors or anomalies is assessed following Grosskopf and Valdmanis [17]. The procedure involves sequential removal of vessels supporting the piece-wise linear frontier to determine how the frontier changes in their absence. A first iteration of this procedure indicated that the RB cost savings estimates declined by $1.18 \%$. Further iterations (a total of four were undertaken) indicated cost savings estimates declined by at most $2.44 \%$ of the savings estimated from the full sample. Hence, the cost savings estimates appear to be robust.

Empirical studies of commercial fisheries commonly use measures of vessel size, length or water displacement, as proxies for capital services (e.g., $[9,16,19]$ ). In this study vessel length is used to measure the rate of capital service flows used to harvest reef fish. It is difficult to know whether this proxy for capital services, or other data measurement errors, bias the estimate of harvest cost savings expected under RB management.

We next examine how predicted vessel activity levels under RB management affect estimated cost savings. An overestimate of per-vessel output under RB management will underestimate RB fleet size and RAC. Suppose that RB-vessels spend 10\% fewer days at sea than are assumed above. In this case, our model predicts that cost savings decline by $\$ 63,000$. The change in the cost 
savings estimate is relatively small because RAC is quite flat over the range of output quantities that are assumed in the analysis.

The long-run equilibrium fleet structure that is assumed in Section 4.2 ignores the role of uncertainty and costly investment reversibility of fishing capital. Unanticipated changes in stock abundance, TAC and relative prices will in general affect the shadow price of fishing capital. The optimal fleet size in a world of uncertainty may differ from the 29-70 vessels that are predicted capable of harvesting the 1993 reef fish catch. ${ }^{23}$ Notice however, that fixed operating costs are not excessive (Table 4) and consequently the estimated cost savings under RB management do not appear particularly sensitive to at least modest changes in fleet size.

An over- or underestimate of internal cost efficiency attained by the RB fleet affects the estimated cost savings due to management reform. Referring to Fig. 2 however, notice that 13 of the 40 class 1 sample vessels $(32.5 \%)$ achieved a cost efficiency score above the 70 th percentile value assumed in our analysis. The sample of 99 vessels that participated in the cost survey represent roughly one-quarter of the 1993 fleet of 387 vessels. If the cost efficiency attained by the sample is representative of the vessel population, 125 vessels should be capable of achieving the internal cost efficiency that is assumed in our analysis. This suggests higher internal cost efficiency may obtain under RB management. If the RB fleet achieves the 80th or 90th percentile level of internal cost efficiency of 1993 class 1 vessels, predicted cost savings increase to $\$ 8.804 \mathrm{~m}$, and $\$ 8.806 \mathrm{~m}$, respectively. However, cost savings are predicted to fall to $\$ 7.629 \mathrm{~m}$ if the 50 th percentile level of internal cost efficiency is attained.

The empirical estimate of the DDF was obtained under the maintained hypothesis that the reef fish harvest technology exhibits NDRS over the range of harvest quantities observed in the 1993 data. This assumption played a role in the interpretation of efficiency for the 1993 data but does not impact the cost savings estimates predicted under RB management. The four-step procedure in Section 4.2 assumes RB vessels harvest scale efficiently and thus the region of the 1993 frontier exhibiting decreasing returns is not relevant for characterizing RB vessel activity levels.

Aggregation of individual reef fish species into output groups, and linear aggregation within output groups, was necessary for model tractability. Data limitations do not permit a thorough assessment of the effects of output aggregation on results. Finally, the analysis assumes that the economic returns to non-reef fishing, i.e., the harvest of $y_{3}$, are not affected by switching to RB management.

\subsection{Institutional considerations}

We have based our estimate of harvest cost savings on the long-run equilibrium fleet structure that is predicted to emerge under RB management. An estimate of long-run benefits can provide a useful benchmark for assessing alternative management options over longer planning

\footnotetext{
${ }^{23}$ The commercial red snapper TAC was increased in 1996 from $3.04 \mathrm{~m}$ pounds (the 1993 level) to $4.65 \mathrm{~m}$ pounds. Our programming model predicts that between 42 and 100 vessels, depending on size, are capable of harvesting the 1993 level of other reef fish plus $4.65 \mathrm{~m}$ pounds of red snapper. This calculation does not control for changes in stock abundance between 1993 and 1996, and must be interpreted cautiously.
} 
horizons. While the predicted revenue gains are expected to accrue concurrent with the elimination of red snapper season closures, the estimated cost savings will not be fully realized until the predicted equilibrium fleet structure emerges. Delays in the transition to the RB equilibrium could take years and may be sensitive to the method used to initially distribute tradable harvest permits [29]. In the shorter term, differences in vessel cost efficiency (Fig. 2) suggest that variable cost savings will be generated as harvest permits are redistributed to cost efficient vessels. ${ }^{24}$ However, these gains will be limited without fleet downsizing. Managers and industry may wish to consider policies to shorten the transition period, for example, compensating vessels that face limited opportunities outside of the reef fish fishery.

A related consideration is the social welfare effects of removing over 300 fishing vessels from the fishery and deploying them in alternative uses in the economy. The reported cost savings implicitly assume that the value of exiting vessel capital is zero. Thomas et al. [24] find that most red snapper fishermen perceive few if any outside earning opportunities. If however the social value of exiting capital is positive, our estimates of the net returns from RB management reform are understated. On the other hand, it is possible that the value of exiting capital is negative if it can cause increased harvesting pressure and management problems in other fisheries. For example, a likely destination for 300 or so exiting vessels is the eastern Gulf reef fish fishery which currently faces similar management problems as the northern region. Ensuring that exiting vessel capital does not create further economic distortions presents a serious challenge for industry and managers. ${ }^{25}$

The estimate of the benefits of RB management reform does not include changes in the cost required to administer the RB management program. Increased monitoring costs under RB management may detract from total benefits reported here [7]. Conversely, RB management could lower administration costs by avoiding frequent regulatory adjustments, which are an unavoidable feature of many controlled access management programs. ${ }^{26}$

Bycatch mortality is likely to change under RB management. Under controlled access, vessels with red snapper permits tend to target red snapper during openings and other species during red snapper closures [24]. Red snapper caught during a closed season, or by non-permitted vessels, are discarded as bycatch. While no formal estimates of total bycatch mortality are available, eliminating seasonal closures will likely reduce red snapper bycatch. Nonetheless, bycatch mortality remains a concern in RB-managed multispecies fisheries. Vessels harvesting multiple reef fish species may choose to discard fish caught in excess of permit holdings, and relative catch levels at the aggregate level may not be aligned with aggregate TAC targets [1]. Squires and Kirkley [23] note that rents in multispecies fisheries are reduced if fisher's ability to adjust output mix in response to economic incentives is restricted under tradable permit programs.

\footnotetext{
${ }^{24}$ Our results indicate that roughly $61 \%(\$ 4.912 \mathrm{~m})$ of cost savings under RB management are variable cost savings.

${ }^{25} \mathrm{An}$ anonymous referee observes that the predicted increase in dockside red snapper prices may not be realized if exiting vessels redirect their harvesting efforts toward other reef fish species that are red snapper consumption substitutes.

${ }^{26}$ Clay Heaton of the Mid-Atlantic Fisheries Management Council reports that the switch to individual transferable quota management in the surf clam and ocean quahog fishery led to a significant reduction staff hours dedicated to clam fishery management.
} 
Lastly, we have focused on 1993, the year that the cost survey data are available. Harvest distortions and depressed dockside prices have persisted from 1991-2001 (see Fig. 3). Changes in stock abundance and species composition, and adjustments to the TAC of red snapper over time make extrapolation of net benefit estimates to other years of the controlled access management program difficult. Nonetheless, it is reasonable to think that benefits similar in magnitude to the 1993 estimates were available throughout 1991-2001.

\section{Conclusion}

This article estimates the potential long-run economic benefits of switching from controlled access management to a property rights-based management program in the northern Gulf of Mexico reef fish fishery. Our results indicate that spreading the red snapper harvest more evenly throughout the year in 1993 would have eliminated market gluts and raised average dockside revenue by $\$ 3.206 \mathrm{~m}$, representing a $48.6 \%$ increase over 1993 red snapper revenues. Significant harvest cost savings of $75 \%$ could have been generated under tradable harvest permits. Eliminating per trip catch limits and seasonal closures, and reallocating harvesting responsibilities to cost efficient vessels could have reduced fleet harvest costs in 1993 by $\$ 8.078 \mathrm{~m}$. The combined revenue gains and cost savings are estimated at $\$ 11.284 \mathrm{~m}$. The northern Gulf reef fish fishery has been managed under distorting regulations from 1991-2002, and economic benefits of similar magnitude were likely available throughout this period.

Our estimate of the potential long-run rent gains assumes that a system of freely tradable harvest permits can be designed and implemented. Designing such a program is likely to be complicated, and implementing such a program may be more difficult [6,21]. These obstacles should be weighed against the economic benefits of management reform, which appear to be large.

\section{Acknowledgments}

We thank seminar participants at Iowa State University, the University of Minnesota, the Second World Congress of Environmental and Resource Economists, and two anonymous referees. Special thanks to Felix Cox, Mike Travis and Peter Emerson. We alone are responsible for any remaining errors and omissions. Potential management implications of this paper do not necessarily reflect the management philosophy of the National Marine Fisheries Service.

\section{References}

[1] L.G. Anderson, Conceptual constructs for practical ITQ management policies, in: P.A. Neher, N. Mollett (Eds.), Rights Based Fishing, Kluwer Academic Publishers, Dordrecht, 1989.

[2] R.D. Banker, Hypothesis tests using data envelopment analysis, J. Product. Anal. 7 (1996) 139-159. 
[3] W.J. Baumol, J.C. Panzar, R.D. Willig, Contestable Markets and the Theory of Industry Structure, Harcourt Brace, Jovanovich, New York, NY, 1982.

[4] K.E. Casey, C.M. Dewees, B.R. Turris, J.E. Wilen, The effects of individual vessel quotas in the British Columbia Halibut fishery, Mar. Resour. Econom. 10 (1995) 211-230.

[5] R.G. Chambers, Y. Chung, R. Färe, Benefit and distance functions, J. Econom. Theory 70 (1996) 407-419.

[6] Committee to Review Individual Fishing Quotas. Sharing the Fish: Toward a National Policy on Individual Transferable Quotas. National Academy Press, Washington, DC, 1999.

[7] P. Copes, A critical review of the individual transferable quota as a device in fisheries management, Land Econom. 62 (1986) 278-291.

[8] D. Dupont, Individual transferable vessel quotas and efficient restructuring of the primary harvesting sector, Ann. Oper. Res. 94 (2000) 275-294.

[9] D. Dupont, R.Q. Grafton, J. Kirkley, D. Squires, Capacity utilization and excess capacity in multi-product privatized fisheries, Resour. Energy Econom. 24 (2002) 193-210.

[10] R. Färe, S. Grosskopf, Theory and application of directional distance functions, J. Product. Anal. 13 (2000) 93-103.

[11] R. Färe, S. Grosskopf, J.E. Kirkley, D. Squires, Data envelopment analysis (DEA): a framework for assessing capacity in fisheries when data are limited, Paper presented at the IIFET Corvallis, Oregon, July $10-15,2000$.

[12] R. Färe, S. Grosskopf, C.A.K. Lovell, Production Frontiers, Cambridge University Press, Cambridge, UK, 1994.

[13] H.O. Freid, S.S. Schmidt, S. Yaisawarng, Incorporating the operating environment into a nonparametric measure of technical efficiency, J. Product. Anal. 12 (1999) 249-267.

[14] J.R. Gauvin, J.M. Ward, E.E. Burgess, Description and evaluation of the Wreckfish fishery under individual transferable quotas, Mar. Resour. Econom. 9 (1994) 99-118.

[15] G. Geen, M. Nayer, Individual transferable quotas in the Southern Bluefin Tuna fishery: an economic appraisal, Mar. Resour. Econom. 5 (1988) 365-387.

[16] R.Q. Grafton, D. Squires, K.J. Fox, Private property and economic efficiency: a study of a common pool resource, J. Law Econom. 18 (2000) 679-713.

[17] S. Grosskopf, V. Valdmanis, Measuring hospital performance: a nonparametric approach, J. Health Econom. 6 (1987) 89-107.

[18] H. Leibenstein, X-inefficiency xists-reply to an xorcist, Amer. Econom. Rev. 68 (1978) 203-211.

[19] K. Segerson, D. Squires, On the measurement of economic capacity utilization for multi-product industries, J. Econometrics 44 (1990) 347-361.

[20] D. Squires, M. Alauddin, J. Kirkley, Individual transferable quota markets and investment decisions in the fixed gear sablefish industry, J. Environ. Econom. Management 27 (1994) 185-204.

[21] D. Squires, H. Campbell, S. Cunningham, C. Dewees, R.Q. Grafton, S.F. Herrick Jr., J. Kirkley, S. Pescoe, K. Salvenes, B. Shallard, B. Turriss, N. Vestergaard, Individual transferable quotas in multispecies fisheries, Marine Policy 22 (1998) 135-159.

[22] D. Squires, J. Kirkley, Resource rents from single and multispecies individual transferable quota programs, ICES J. Mar. Sci. 52 (1995) 153-164.

[23] D. Squires, J. Kirkley, Individual transferable quotas in a multiproduct common property industry, Can. J. Econom. 24 (1996) 318-342.

[24] J.S. Thomas, G.D. Johnson, C.M. Formechella, C. Riordan, Perceived social and economic effects of current management policies on Red Snapper Fishermen operating in the Gulf of Mexico, Unpublished report, University of Southern Alabama, 1993.

[25] US Department of Labor, Bureau of Labor Statistics, Employment and Earnings, 1994.

[26] J.R. Waters, An Economic Survey of Commercial Reef Fish Vessels in the U.S. Gulf of Mexico, National Marine Fisheries Service, National Oceanic and Atmospheric Administration, Unpublished report, July 1996.

[27] J.R. Waters, Quota management in the commercial Red snapper fishery, Mar. Resour. Econom. 16 (2001) 65-78.

[28] Q. Weninger, Assessing efficiency gains from individual transferable quotas; an application to the mid-Atlantic surf clam and Ocean Quahog fishery, Amer. J. Agric. Econom. 80 (1998) 750-764. 
[29] Q. Weninger, R.E. Just, An analysis of transition from limited entry to transferable quota: non-marshallian principles for fisheries management, Nat. Resour. Modeling 10 (1997) 53-83.

[30] J. Wilen, F. Homans, Marketing losses in regulated open access fisheries, Paper presented to the Sixth International Conference IIFET, Paris, July, 6-9, 1992. 